\title{
AC 2011-2419: TOOLS TO CRAFT ETHICAL BEHAVIOR
}

\section{Martin S. High, Oklahoma State University}

Marty High is an Associate Professor of Chemical Engineering at Oklahoma State University. His academic interests include teaching in all areas and at all levels of chemical engineering with a focus on instruction in thermodynamics and mass transfer. His research interests are in the areas of mass transfer in polymeric systems, corrosion modeling, equation of state development and refinery catalysis. Marty also writes in the area of sustainability and on the intersection of law, science and society. He received his engineering education at Penn State (B.S., M.S., and Ph.D.) and earned his law degree (J.D.) from the University of Tulsa.

\section{R. Steve Harrist, Oklahoma State University}

Steve Harrist is associate professor in the School of Applied Health and Educational Psychology at Oklahoma State University.

\section{Scott D Gelfand, Oklahoma State University, Dept. of Philosophy}

Scott Gelfand is Director of the OSU Ethics Center and an Associate Professor of Philosophy. Scott specializes in theoretical ethics, applied ethics and moral psychology. 


\title{
Tools to Craft Ethical Behavior
}

\begin{abstract}
Engineering educators provide students a wide variety of tools and skills: mathematics, chemistry, physics, computer programming, and discipline specific knowledge. All of these tools are designed to be multipurpose and adaptable to whatever problem the student will face in professional life. However, one area in which our students tend to be underprepared and tend to be lacking in analogous "tools" to solve problems is in ethics. Ethics is typically taught by showing students case study after case study that exemplify unethical behavior. Although highly useful, case studies tend to show students what not to do, rather that demonstrating the proper course of action taken. This paper looks at a complementary method to case studies.
\end{abstract}

Standard ethics classes neglect the topic of moral psychology. Specifically, these classes do not teach students why people act unethically, and they do not provide students with strategies that they can use in order to increase the likelihood that they will act in accord with their own ethical commitments and/or the ethical codes of their professions. We are designing a class, which will be electronically delivered and can stand alone as a seminar or be added to the curriculum of traditional Research Ethics classes, will expose students to video clips containing re-enactments of published empirical studies that demonstrate why people act unethically. After a discussion of each clip, each individual student will be guided through a two-part exercise. The first part, developing a Personal Inventory Report, will help the student engage in reflection in order to determine what sorts of situations the student might find ethically challenging. The student will then develop a personal plan (Adaptive-Strategies Report) addressing what strategies they might use in order to increase the likelihood that they will act ethically in challenging situations (that is, the situations arrived at while developing the Personal Inventory Report). The Adaptive Strategies Report will help the student: 1) recognize when an ethically challenging situation; and 2) act ethically in ethically challenging situations (that is, apply the strategies developed for the Adaptive-Strategies Report). The products of this exercise - Personal Inventory Report and Adaptive-Strategies Report - will be provide to the student, and they can be used throughout the student's career, especially when in a new professional situation.

\section{Introduction}

The number of incidents of ethical breaches and research misconduct is worrisome. A recently released study reported that the frequency of research misconduct and under-reporting of research misconduct among those receiving funding from the U.S. Department of Health and Human Services is three instances per year for every 100 researchers. ${ }^{1}$ In fact, the true annual rate of unethical behavior is greater than three incidents per 100 researchers (it may be far greater), because this study did not take into account unethical behavior that does not constitute research misconduct, e.g., managing conflicts of interest or misusing grant funds. And as the aforementioned study reveals, the problem of under-reporting research misconduct is even worse. Arguably, engineering educators must place a higher priority on ethics education.

Until recently, ethics education for scientists and engineers was limited and informal, and it was provided almost exclusively by graduate students' mentors/advisors. ${ }^{2}$ The efficacy of this 
"educational" model has been criticized for a number of reasons ${ }^{3,4}$, including that mentors/advisors may not have time (or take the time) to teach ethics to their students ${ }^{5}$ as they are under various pressures to perform their faculty duties, most of which do not permit the time to instruct students in ethics. Although graduate students in engineering and the sciences still rely on their mentors/advisors for ethics education, universities now routinely offer research ethics classes. These classes are typically short-term courses that introduce students to ethical decisionmaking (ethical theory and case-based reasoning) and compliance (federal and other regulations related to research). Research indicates that research ethics classes do increase students' knowledge and slightly increase decision-making skills, but they are not very effective. ${ }^{6}$ Accordingly, it has been suggested that more comprehensive classes and/or internet tutorials might be more effective than standard Research Ethics classes. ${ }^{7}$

One crucial topic that standard research ethics classes neglect is moral psychology. Specifically, typical classes in ethics teach students why people act unethically, but they do not provide students with useful strategies to increase the likelihood that they will act in accord with their own ethical commitments and/or the ethical codes of their professions. This last is important given the frequency of unethical behavior.

\section{Why People Act Unethically}

Schwart $\mathrm{z}^{8}$ concludes, based on empirical findings, that there are five general reasons why one might violate an ethical code: 1) self interest - financial concerns, desire to be a star or to make one's job easier; 2) dissatisfaction - with one's job or compensation; 3) environment peer pressure, supervisors' pressure or lack of concern with compliance, an organizational culture that does not stress ethics, and organizational structure; 4) companies' interest - the violation would help the company; and 5) ignorance. Significantly, violations motivated by any of the first four reasons are most likely intentional or knowing. (A recent perusal of the disciplinary actions in a number of state engineering societies reveals that the most common ethical violations are intentional or knowing. To wit, the most common violations are practicing outside of the area of competence of the engineer and practicing without a license.) Schwartz's findings are not the end of the story. After all, only some of those who are, for example, unsatisfied with their compensation (Schwartz's reason \#2) violate ethical codes. Hence, there must be reasons in addition to the ones discussed by Schwartz, foundational reasons, which explain why some people act ethically, while others in the same or similar situations do not do so.

The most obvious answers as to why only some people act unethically, while others do not act unethically are: 1) those who act unethically are not aware of the relevant ethical rules and principles; or 2) those who act unethically are less virtuous; that is, they are less honest, loyal, caring, etc.... But, as pointed out above, much unethical behavior involves the violation of obvious, well-known ethical rules and principles. Hence, it follows that those who act unethically are less virtuous. BUT research suggests that this conclusion is false (or at least incomplete).

\section{Situationism}

John Doris, Gilbert Harmon and others claim that findings in empirical psychology demonstrate that character is not the primary influence on whether one will act ethically. ${ }^{9}$ They 
claim that external factors play a greater role in one's choice of behavior than is commonly suggested. A well-known study demonstrating this claim involves two groups of subjects (who are unaware that a study is underway) who upon completing a telephone call and exiting a phone booth observe a stranger dropping some files onto the ground. ${ }^{10}$ The first group consisted of twenty-five randomly chosen people. Twenty-four out of the twenty-five people who exited the phone booth and saw a stranger drop some files continued walking without offering assistance, while one person offered to help pick up the files. Then, the phone booth was rigged in such a way that when a person completed her/his call (and hung up the phone), her/his coin was returned. The second group consisted of sixteen randomly chosen people who made calls when the phone was rigged in this manner. Surprisingly, fourteen of these sixteen people helped the stranger who dropped the files. (Less than $5 \%$ of the first group offered assistance, and more than $85 \%$ of the second group offered assistance.) Presumably, the ethical characters of those in the second group were not better than the characters of those in the first group. ${ }^{1}$ The phone booth study (the results of which are confirmed by other studies) led Doris to theorize that situation plays the greatest role in determining whether one will act ethically. Doris calls this theory situationism. ${ }^{11}$

Although most of those responding to Doris's research agree that the difference in the situations (having the coin returned or not having the coin returned) must be responsible for the behavioral differences, there is broad disagreement over what are the implications of this and similar studies. ${ }^{12}$

\section{2-Level Model of Decision-Making}

A promising model of decision-making, which is consistent with (and may help to explain) empirical studies like the phone booth study, claims that people operate on (at least) two different levels when they make decisions (or respond to questions): level-1 (gut/intuitive level) and level-2 (analytic/contemplative level). ${ }^{13}$ (Although this model is committed to two levels, these levels may not be distinct. Hence, it may be more accurate or clear to conceive of level-1 and level-2 as endpoints on a continuum. At any given time, a person may be at level-1, somewhere between level-1 and level- 2 or at level-2.) When operating at level-1 people are not consciously thinking about what they are doing, and emotions often drive level-1 behavior. For example, when one is driving to work, one is operating at level-1. One does not think about when to turn or what to do when a traffic light changes color; it's like that person is on automatic pilot. However, if the road is unexpectedly closed, the person may shift to level-2 (or the person may move away from level-1 and closer to level-2). One can then be creative or analytic and think about which route to take. Similarly, when one is talking, usually one does not think about or carefully choose the words one uses; the words just flow - level 1. If, however, one is being interviewed by a prospective employer, the person is cautious and carefully chooses her/his words - level-2 (or one might say this person has moved closer to level-2 and away from level1). Finally, as stated above, emotions often drive level one behavior. We are not surprised to hear someone say: "I didn't mean what I said. It slipped out when I was angry. I wish I would have thought before I spoke.” Comments like these indicate that the speaker was operating at level 1.

\footnotetext{
${ }^{1}$ Doris does not suggest that any inferences can be drawn from this example with respect to gender/age/etc... of those using the phone booth.
} 
1) This is good, but you neglect one important concern. Isn't it possible, even likely, that people would begin to doubt their doctors if they discovered that doctors lied about treatment options in order to bring about a better state of affairs?

\section{Relevance of 2-Level Model of Decision-Making}

This same two-level approach to decision-making is applicable to ethics. Throughout the day, people are confronted, even bombarded, with situations that have an ethical component. Most of the time, people do not even recognize that this ethical component is present (unless they are reminded). They already figured out what to do in these situations. They act out of habit and emotion and stay at level-1. It's like driving the same route to work every day. For example, most of us do not move to level-2 when we go shopping for a toothbrush. Yet, we may know or suspect that the toothbrush was imported and that buying it may contribute to the problem of childhood labor or may hurt the American economy. If someone points out this last fact, we may move to level-2 and think about (analyze) whether buying the toothbrush is consistent with our basic ethical commitments. But once we decide what to do (in most instances), we stop thinking about the ethical component and we form something like a habit. Put differently, most of the time when we buy a toothbrush we are at level-1. Similarly, we may not think twice about patronizing a boutique coffee shop, even though when we think about it we know that we could make coffee at home and donate the savings to a reputable charity. Again, when someone points this out we think about whether our behavior is ethically acceptable. But once we decide to patronize the coffee shop (or not), it becomes habit or at least we no longer think about the question of whether buying this coffee is ethical. That is, we stay at level-1. Throughout the day people are confronted with situations, like those mentioned above, that have an ethical component. Most of the time their behavior is automatic or habitual; that is, most of the time people operate at level-1. At the risk of being repetitive, occasionally people are shaken up; that is, they are thrust into level-2. A friend or colleague may remind a person about the problem of childhood labor and ask this person to imagine what it would be like to know one's own children were making toothbrushes in sweat shops.

Significantly, one way to prompt people to move to level-2 is to increase their awareness of this decision-making model. If people are taught that in certain situations they are prone to make mistakes, they can teach themselves to slow down in these situations in an effort to avoid error. That is, they can teach themselves to move to level-2. Logic/philosophy professors have been teaching students this error-avoidance mechanism for years. Studies reveal that most people are good at making deductive inferences, and people regularly do so automatically - level-1. If we tell a person, "If the train is late, John won't make the lecture," and then tell her/him, "The train was late," he will, without hesitation, reflection or analysis, invariably conclude: "John will not make the lecture." But there are some situations in which people's level-1 thinking fails. For example, if someone states an abstract conditional - if $\mathrm{X}$, then $\mathrm{Y}$ - people often conclude that this statement implies if not $\mathrm{X}$, then not $\mathrm{Y} .{ }^{14}$ Philosophy/logic professors know about this common fallacy, and they warn/inform their students accordingly. Students armed with this knowledge slow down when they see a conditional statement; they move to level-2 (or closer to level-2) and are more likely, as a consequence, to avoid this fallacy. (And many people have 
learned to move to level-2, in some situations, on their own. One who knows that they have a way of offending her/his supervisor, for example, may consciously decide to slow down and be cautious and creative - level-2 - when a supervisor is present - assuming one does not want to offend one's supervisor).

This two-level decision-making model helps explain how people react to novel ethical situations. Consider someone who, for the first time in the person's life, is approached by a homeless person asking for money. This person may be uncomfortable, scared or nervous. The person may look away or quickly decline the request. That person was at level-1, and emotions drove the choice (not to comply with the wishes of the homeless person). But when the person walks away from the homeless person and the fear decreases, the person may recognize the ethical aspects of the situation. The person may be confused and feel driven to try to figure out how to respond in case a similar situation arises in the future. The person moves to level-2, and may believe that helping people in need is ethically good, but he or she may be unsure whether donating money to this person will help. Or they may have other qualms/ideas/thoughts. They may, for example, wonder whether helping one homeless person implies that they should help all homeless people. Eventually the person makes a decision. Over a period of time a habit is formed, and the person begins to respond to this and similar situations without thinking. They stay at level-1. Interestingly, if the person is in a particularly good or bad mood, they may alter their behavior (and may be unaware of the reason why the behavior was altered or may not realize that behavior was altered). ${ }^{15}$ Similarly, if they are somehow shaken up, they may rethink the situation. If, for example, one reads a newspaper article explaining that the economy has forced many hard-working people out of their homes (and one of the people described in the article reminds the person of himself or herself), they may shift to level- 2 when they next sees a homeless person. At level-2 they are likely, at the very least, to question whether the habitual behavior is right, and they may begin to think anew about how to respond.

This decision-making model provides two possible explanations for the results of the telephone booth study (and other similar studies). People regularly see others in need of minimal assistance, whether they see someone who needs assistance carrying groceries to a car, picking up some dropped items or putting the final touches on a research project before a deadline passes. During most of one's waking hours, one operates at level-1. For example, when a person passes someone in need of (minimal) assistance; this person is likely on the way to an appointment or a class or trying to finish a task. How one responds or recognizes that they are confronted with an ethical situation - whether to help the person in need of assistance - is to a considerable extent a function of habit and one's emotional states. [This last, that emotion plays a significant role in ethical/ethical behavior at level-1 is important. Numerous studies demonstrate both that one's ability to recognize an ethical situation and how one responds to an ethical situation are partly or wholly a function of emotions. ${ }^{16}$ Neuroimaging studies, which reveal that ethical cognition implicates the emotion parts of the brain, support this claim. ${ }^{17}$

When one completes a phone call and the coin is returned, they might feel a sense of good will (or a similar positive emotion); they received something of value (albeit little value) that was unexpected. In this emotional state - feeling a sense of goodwill (or a similar positive emotional state) -- while at level-1, people might be inclined help someone in need, especially if doing so is not costly. Although this last may seem to be a stretch, it's not unsupported. Research demonstrates that subjects induced into a good mood are significantly more helpful than those 
not so induced (Isen and Levin, 1972). "We feel good when we feel good. This may play an important role in ethical education" (Prinz, 2007). As explained above, at level-1 people's emotions often drive ethical behavior.

An alternative explanation, which is also consistent with the two-level model, is that those who receive the coin are surprised. Having a coin returned after making a call is unexpected; it is not the norm. In order to make sense of what happened, people move (they may be thrust) to level-2 (or move away from level-1 toward level-2). A person might be driven by a desire to explain this (relatively) unusual occurrence - to make sense of the world - and they might conclude something as simple as: "I guess the phone is broken." Or, "I did not deserve to get my coin back; it belongs to the phone company." Whatever the case, because this person is operating at level-2 (or closer to level-2 than usual) when they exit the phone booth and sees that someone dropped some files, they act differently from the way in which they (or others) normally act. This explains the difference in experimental results between those whose coins were returned and those whose coins were not returned. Importantly, one may not be aware of the fact that they are operating at level-2 (or moving closer to level-2). In the same way one takes a detour to work without being aware that one is at level-2 (unless it is pointed out to this person), one may help a person pick up the dropped files without being aware that they thought about doing so. But if that person is questioned about the behavior, they will likely be able to explain how to conclude that they should help. This is not the case for level-1 behavior.

Whether the experimental subjects were operating at level-1 or level-2 is not crucial for the purpose of ethics education. What is crucial is teaching researchers about this model of decision making AND teaching them about the role of emotion in level-1 thinking and when it is important to move to level-2. This knowledge (combined with a desire to act ethically, which, as explained below, is the norm) may increase the probability that one will act ethically. For example, if researchers know that falsification and fabrication are the most common types of research misconduct and they know that people are more likely to act unethically when in a group situation, they are more likely to move to level-2 when they are in a group situation when dealing with unwanted experimental results. This is similar to students moving to level-2 when faced with an abstract conditional statement (If A, then B). In addition, learning about situationism may motivate students to take Doris's advice and try to avoid putting themselves in ethically challenging situations (Doris, 1998). For example, researchers might want to try to avoid procrastinating and waiting for the last minute to finish projects in order to avoid feeling/believing that cutting corners (fabricating or falsifying) might be necessary. After all, situationism suggests that it is difficult to accurately predict how one will act in ethically challenging situations.

Knowing when, in what situations, and in what emotional states or mindsets one might be disposed (or more disposed than usual) to act unethically is crucial. It is during these times or in these situations that one must be aware of one's emotional states and be ready to utilize strategies that help her/him shift to level-2.

2) This is good, but you neglect one important concern. Isn't it possible, even likely, that people would begin to doubt their doctors if they discovered that doctors lied about treatment options in order to bring about a better state of affairs? 


\section{Emotions and Ethical Judgment}

Significantly, research reveals some of the situations, conditions or emotional states that affect the probability one will act unethically. One's emotional state, for example, whether one's emotions are "hot" or "cold" (whether one is angry or calm or whether one is happy or sad) affects both judgment and behavior. (As explained above, this may explain the phone study.) And external factors affect judgment and behavior. For example, some institutional structures are conducive to ethical behavior and having social support contributes to ethical behavior. (Of course, external factors do not directly affect judgment and behavior. Rather, they affect emotional states and other inner states, which then affect judgment and behavior. But since these external factors can be conceived of as the proximate causes of behavior, it is accurate to attribute judgments and behaviors to these external factors.) Finally, one's personal dispositions or psychological triggers affect judgment and behavior (Gaudine \& Thorne, 2001). These triggers vary from person to person. Consider a person with an unusually strong desire to be accepted by one's peers and supervisors, which is manifested by an unusually strong desire to avoid conflict. They may be tempted (or feel the need to succumb to external pressure) to condone the behavior of a colleague who fabricated data, while one who does not share this trigger may not have any temptation (or may find it easier to resist external pressure) to condone this behavior.

Thus, it's important for students to learn about the role emotions typically play in ethical judgment and behavior, what are their own personal triggers, and, of course, as situationism makes clear, that external factors, like organizational structure, also affect judgment and behavior. As Harvey James points out: "While helpful, ethics training and corporate codes are neither necessary nor sufficient in promoting ethical behavior within firms... [the appropriate organizational structure] which is distinguished from corporate culture, is necessary" (James, 2000).

\section{Strategies for Buy-In}

Although most students and professionals want to act ethically, there are strategies one can use to encourage them to "buy into" a class/program addressing the issues discussed above. Interestingly, these strategies, which can be applied in a way that increases "buy in" and ethical behavior, provide an additional explanation as to why one might act ethically or unethically. For example, as Robert Cialdini points out, people strive to be seen as consistent, whether this is through their words, acts, attitudes, etc... (Cialdini, 1993). Accordingly, students taking a class on how to avoid unethical behavior should be encouraged to think about how acting ethically is consistent with their words (assuming they have discussed ethics before). Cialdini discusses other principles or strategies - "social proof" (what other people are doing) and "liking" - that might play a role in getting students and professionals to "buy in". (As is the case with "consistency," these other principles and strategies - "social proof" and "liking" - also explain why people might act unethically.) Charles Taylor's claims concerning people's natural desire to be oriented to the good also serves the functions of increasing "buy in" and explaining why people might act ethically or unethically. According to Taylor, people want to be connected to what they see as good or of fundamental value (Taylor, 1992) Awareness of the desire to be oriented to the good can motivate people to act ethically. In addition, this drive to be oriented to 
the good explains why people might try to justify in their own minds unethical behavior, thereby convincing themselves that this behavior is, in fact, ethical.)

\section{Future Efforts and Applications to the Ethics Classroom}

In the coming semesters, we will be designing, administering and testing the effectiveness of an ethics program for engineers and scientists that, unlike traditional ethics classes, focusing to a considerable extent on why people violate ethical codes or act immorally. The overall goal is to help students and professionals ascertain general influences on ethical action and specific factors influencing their own ethical behavior, and use this information to develop strategies that will help them overcome the temptation to violate an ethical code or act unethically. A recent study concluded that there are five general reasons as to why one might violate an ethical code: 1) self interest - financial concerns or make one's job easier; 2) dissatisfaction - with one's job or compensation; 3) environment - peer pressure or supervisors' pressure or lack of concern with compliance; 4) Companies' interest - the violation helps the company; and 5) Ignorance. ${ }^{18}$ Violations for any of the first four reasons are likely intentional. Significantly, most ethics classes for researchers, focus almost exclusively on: 1) introducing students to ethical theory; 2) how to resolve a moral dilemma; and 3) complying with federal and other regulations and ethics codes. ${ }^{19}$ These three foci are important, even necessary. But limiting ethics education to these three foci without addressing why people act unethically or what factors contribute to unethical behavior overlooks critical factors that influence ethical action.

Literature Cited

\footnotetext{
${ }^{1}$ Titus, Sandra L.; Wells, James A.; and Rhoades, Lawrence J., “Repairing Research Integrity,” Nature, Vol. 453 (2008), p. 980-983.

${ }^{2}$ Mathur R, Offenbach S., "Preliminary Observations on Faculty and Graduate Student Perceptions of Questionable Research Conduct." Investigating Research Integrity: Proceedings of the First ORI Research Conference on Research Integrity, http://ori.hhs.gov/documents/proceedings_rri.pdf, (2002), pp. 35-40.

${ }^{3}$ Brown, S., \& Kalichman, M.W. "Effects of Training in the Responsible Conduct of Research: A Survey of Graduate Students in Experimental Sciences," Science and Engineering Ethics, 1988, Vol. 4, 487-98.

${ }^{4}$ Folse, K.A. "Ethics and the Profession: Graduate School Training," Teaching Sociology, (1991), Vol. 19, pp. 34450.

${ }^{5} I d$.

6 Powell, Sean T.; Allison, Matthew A.; and Kalichman, Michael W., "Effectiveness of a Responsible Conduct of Research Course: A Preliminary Study," Science and Engineering Ethics, Vol. 13, No. 2, (June 2007), pp. 249-64.

${ }^{7}$ Id.

${ }^{8}$ Schwartz, Mark, "The Nature of the Relationship between Corporate Codes of Ethics and Behaviour," Journal of Business Ethics, Vol. 32, No. 3, (August 2001), pp. 247-62.

${ }^{9}$ Doris, John, "Persons, Situations, and Virtue Ethics," Nous, Vol. 32, No. 4, (1998), pp. 504-30.; Doris, John, "Lack of Character: Personality and Moral Behavior, New York: Cambridge University Press, 2002; Harmon, Gilbert, "Moral Philosophy Meets Social Psychology: Virtue Ethics and the Fundamental Attribution Error, Proceedings of the Aristotelian Society (1999), pp. 315-31; Harmon, Gilbert, "No
} 
Character or Personality,” Business Ethics Quarterly, Vol. 13 (2003), pp. 87-94; and Vranas, Peter B.M., "Indeterminacy Paradox: Character Evaluations and Human Psychology," Vol. 39, No. 1, (2005), pp. 1-42. ${ }^{10}$ Isen, A.M. \& Levin, H., "Effect of Feeling Good on Helping: Cookies and Kindness," Journal of Personality and Social Psychology, Vol. 21 (1972), pp. 384-88.

${ }^{11}$ Note 9, supra.

${ }^{12}$ See Merritt, Maria, "Virtue Ethics and Situationist Personality Psychology," Ethical Theory and Moral Practice, Vol. 3, (2000), pp. 365-83; Sreenivasan, Gopal, "Character and Consistency: Still More Errors," Vol. 117 (July 2008), pp. 603-12; and Arjoon, Surendra, “International Journal of Management Reviews," Vol. 10, No. 3, (2008), pp. 221-43.

${ }^{13}$ Recker, Doren, "How to Confuse Organisms with Mousetraps: Machine Metaphors and Intelligent Design," Zygon, forthcoming; Sloman, Steven A., "The Empirical Case for Two Systems of Reasoning," Psychological Bulletin, Vol. 119, No. 1 (January 1996), pp. 3-22; Wason, P. C. \& Evans, J.St.B.T., "Dual Processes in Reasoning." Cognition Vol. 3, No. 2, (1975), pp. 41-54; Haidt, Jonathan, "The Emotional Dog and Its Rational Tail: A Social Intuitionist Approach to Moral Judgment," Psychological Review, Vol. 108, No. 4, (October 2001), pp. 814-834.

${ }^{14}$ Wason, P. C. \& Evans, J.St.B.T., "Dual Processes in Reasoning." Cognition Vol. 3, No. 2, (1975), pp. 41-54.

${ }^{15}$ Darby, B.W. \& Jeffers, D. "The Effects of Defendant and Juror Attractiveness of Simulated Courtroom Trial Decisions," Social Behavior and Personality, Vol. 16, No. 1 (1988), pp. 39-50; Schnall, S.; and Haidt, J.; and Clore, G.L., "Disgust as Embodied Moral Judgments," cited in Prinz, Jesse, The Emotional Construction of Morals, New York: Oxford University Press, 2007.

${ }^{16}$ Wheatley, T \& Haidt, J., "Hypnotically Induced Disgust Makes Moral Judgments More Severe, Psychological Science, Vol. 16, No. 10, (2005), pp. 780-84; Fogus, J.P. \& Bower, G.H., "Mood Effects on Personal Perception Judgments," Journal of Personality and Social Psychology, Vol. 51 (1987), pp. 53-60.

${ }^{17}$ Greene, J.D. \& Haidt, J. “How (and Where) Does Moral Judgment Work?” Trends in Cognitive Sciences, Vol. 6, No. 12, (December 2002), pp. 517-23.

${ }^{18}$ Schwartz, note 8, supra, at p. 254.

${ }^{19}$ Powell, note 6, supra. 